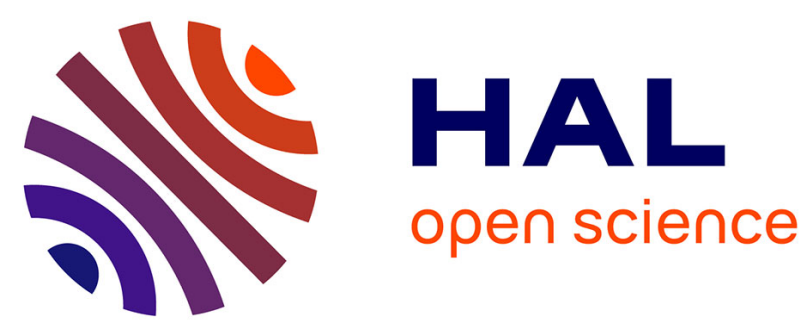

\title{
DEVELOPMENT OF HIGH DENSITY FIBER REINFORCED SILICON CARBIDE FCVI COMPOSITES
}

\author{
Y. Roman, D. Stinton, T. Besmann
}

\section{- To cite this version:}

Y. Roman, D. Stinton, T. Besmann. DEVELOPMENT OF HIGH DENSITY FIBER REINFORCED SILICON CARBIDE FCVI COMPOSITES. Journal de Physique IV Proceedings, 1991, 02 (C2), pp.C2-689-C2-695. 10.1051/jp4:1991283 . jpa-00249873

\section{HAL Id: jpa-00249873 https://hal.science/jpa-00249873}

Submitted on 1 Jan 1991

HAL is a multi-disciplinary open access archive for the deposit and dissemination of scientific research documents, whether they are published or not. The documents may come from teaching and research institutions in France or abroad, or from public or private research centers.
L'archive ouverte pluridisciplinaire HAL, est destinée au dépôt et à la diffusion de documents scientifiques de niveau recherche, publiés ou non, émanant des établissements d'enseignement et de recherche français ou étrangers, des laboratoires publics ou privés. 
Colloque C2, suppl. au Journal de Physique II, Vol. 1, septembre 1991

\title{
DEVELOPMENT OF HIGH DENSITY FIBER REINFORCED SILICON CARBIDE FCVI COMPOSITES
}

\author{
Y.G. ROMAN*, D.P. STINTON* ${ }^{*}$ and T.M. BESMANN* * \\ * Centre for Technical Ceramics, P.0. Box 595. \\ NL-5600 AN Eindhoven, The Netherlands \\ * "Oak Ridge National Laboratory, Metals and Ceramics Division, \\ P.O Box 2008, BIdg. 4515, Oak Ridge, Tennessee 37831-6063, \\ U.S.A
}

\begin{abstract}
Silicon carbide continuous fiber reinforced composites are prepared by Forced flow thermal gradient Chemical Vapor Infiltration. In order to obtain high density and homogeneous ceramic composites the effects of time and thermal gradient across the preform are studied during infiltration. Cross sections of the infiltrated composites are studied with the aid of optical microscopy and image analysis.

This manuscript gives an impression of the experimental composite densities and density gradients achieved and critical aspects that play a role in the infiltration process.
\end{abstract}

\section{Introduction}

Fiber reinforced ceramic composites are known to behave in a more ductile manner than do their monolithic counterparts. For many high temperature applications, hardness, corrosion and oxidation resistance but also toughness and thermal shock resistance are necessary requirements. Ceramic composite materials can replace metals in several applications like gas turbines parts, in engines or as aerospace and structural elements also because of their high strength to density ratio.

Process routes to manufacture continuous fiber reinforced ceramic composite materials that are commonly used are sintering, hot pressing or the Chemical vapor Infiltration (CVI) process. The advantages of this last process are the in situ deposition of a interfacial layer on the fibers to enhance the fiber pullout effect and the low process temperatures. Thermal degradation of the fibers or mechanical damage to the fibers is excluded and are important features of the CVI process. The matrix material deposited is of high purity and resulting composite porosity is low.

Primarily, two different CVI methods are being used i.e. the ICVI and the FCVI method. The former stands for the isothermal isobaric process whereas the latter one means the forced flow thermal gradient CVI process [1]. This (faster) FCVI process is 
used in this study to densify nicalon preforms.

Density gradients across the preform after the densification has ended are to be avoided in order to obtain good mechanical properties.

An objective of this study is to optimize the matrix distribution for the FCVI fiber reinforced processed composites.

The effect of both the thermal gradient across the preform and time effect during densification on the density of the fiber reinforced composites is studied.

\section{Experimental procedure}

The ORNI FCVI process utilizes both thermal and pressure gradients to reduce infiltration duration as compared with the ICVI method. Figure 1 illustrates the ORNL schematic experimental setup.

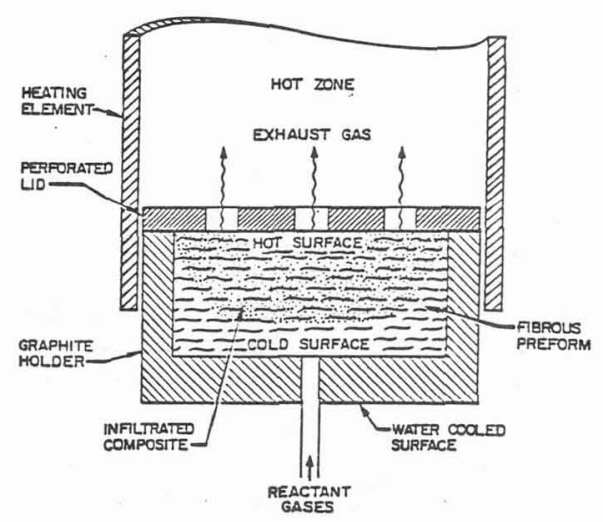

Figure 1.

Forced flow thermal gradient reactor configuration

The porous preforms used in this study are made out of cylindrical layers of nicalon plain weave cloth which are stacked in a graphite holder.

The cloth layers are oriented in a 0-30-60-90\% orientation into the graphite retaining holder and thus providing a two dimensionally reinforcement. The holder is placed on a watercooled gas injector in the reactor furnace which cools the bottom side of the preform. The top side of the preform holder is positioned in the hot zone of the furnace and maintained at $1200^{\circ} \mathrm{C}$ so that a thermal gradient is present during the densification process. The gas enters the preform from the bottom side and flows both axially and radially through the preform. The matrix material will preferentially deposit on the top side of the preform caused by its higher temperature. Porosity of the top decreases whereas density and thermal conductivity increase. Consequently the deposition front moves from top to bottom and densifies the whole preform untill the reduction in gaspermeability of the preform causes the backpressure (i.e. the pressure in the gasinjector) to rise to 1280 torr and the process is terminated.

Silicon carbide is deposited on the fibers by decomposition of methyltrichlorosilane $\left(\mathrm{CH}_{3} \mathrm{SiCl}_{3}\right)$ in hydrogen.

Prior to this SiC infiltration the fibers are coated with a thin layer of pyro-carbon to prevent chemical damage of the fibers by the chlorine present in the MTS and enhance fiber pullout by 
reduction of the interfacial bonding. Propylene in argon is used as the precursor of the carbon layer at a temperature of $1100^{\circ} \mathrm{C}$ and 50 torr total pressure.

\section{Results}

\subsection{Infiltration versus time}

In a reactor (51 $\mathrm{mm}$ inside diameter) infiltration versus time was studied. Four identical preforms are made out of nicalon cloth layers. Fiber content of the preforms is 39 volo and each fiber bundle consisted of 500 filaments.

The runs are interrupted after 9.0, 22.3, 27.6, and 34.8 hours of infiltration and weighed. The 34.8 hour run represents a complete densified composite i.e. the backpressure shutoff setpoint of 1280 torr was reached.

The composite samples were cut into three slabs in radial direction and grounded. Top (hot face), middle and bottom (cold face) slabs were weighed and measured to estimate the bulk composite density of each slab.

\subsubsection{Overall infiltration}

The resulting weight gain of the preforms versus time caused by the matrix deposition is plotted in figure 2 .
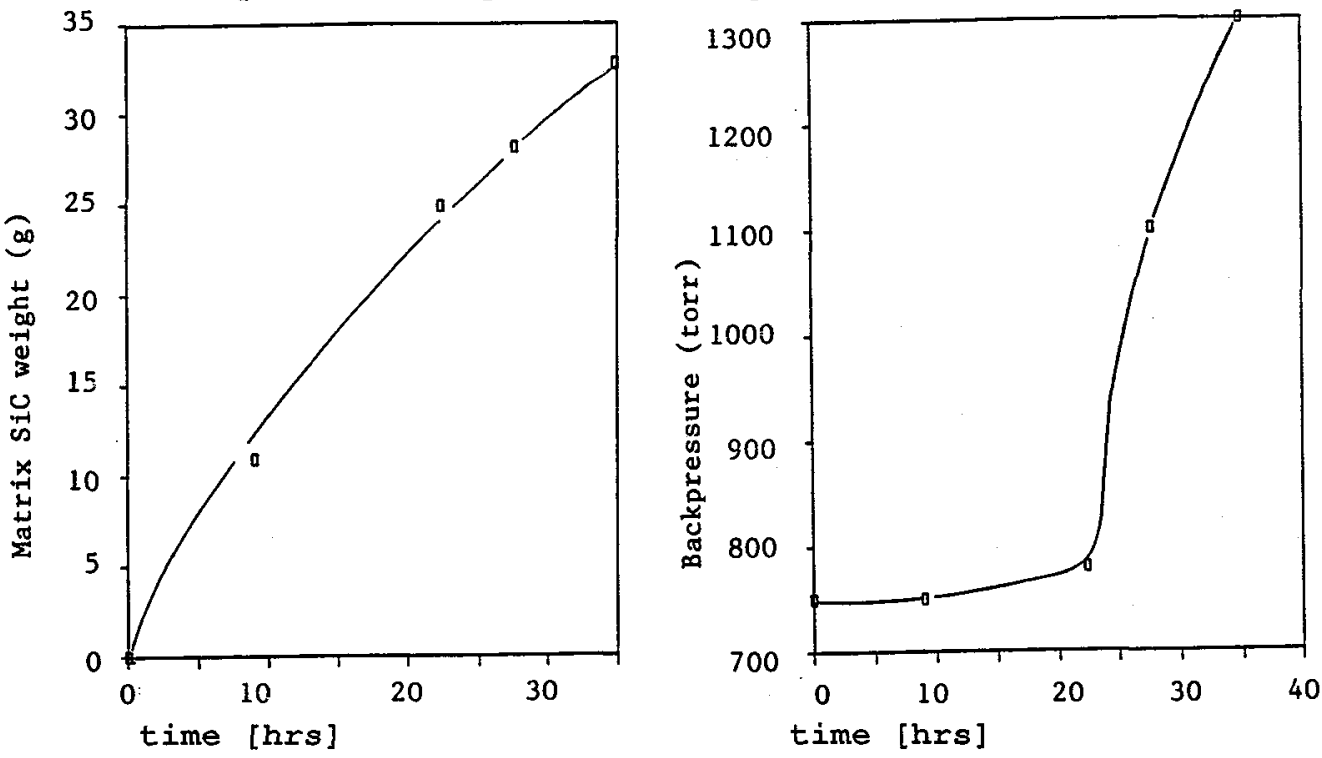

Fig 2. Matrix weight dependency on time

Fig 3. Backpressure increase as a function of time

As can be seen the weight increase is not a linear function of time. During the first hours the infiltration is rapid $(1.3 \mathrm{~g} / \mathrm{hr})$ but levels off as time proceeds $(0.6 \mathrm{~g} / \mathrm{hr})$ untill complete infiltration has taken place. An explanation for this phenomenon is that deposition takes place in the fiberbundles first (on the 
filaments) thus increasing the surface area. When the outer neighbouring filaments touch each other the bundle is sealed preventing more gas to enter and the surface area is greatly reduced as is the weight gain. Closed pores in the bundles are the consequence. Here after the big pores between the fiber bundles (i.e. cloth layers) start to fill with the matrix material.

\subsubsection{Infiltration gradients}

The bulk densities of the composite slabs (top, middle and bottom section) are plotted as a function of time in figure 4 .

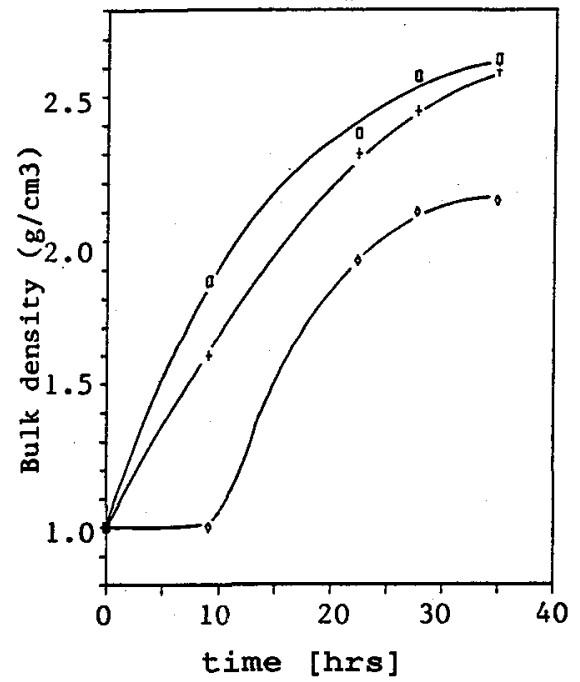

Figure 4. Composite bulk density versus time and position in axial direction

a top

+ middle

0 bottom

The initial density of the uninfiltrated preform is $1.00 \mathrm{~g} / \mathrm{cc}$. The top slab staxts densifying rapidly because of the higher temperature whereas the bottom slab only starts to densify slowly and primarily after appr. 10 hours. As time proceeds densification gain is less rapid for the top slab. The cold face densifies rapidly at this stage. After 20 hours of densification the whole preform densifies (more or less) in a homogeneous way. After complete infiltration i.e. when the backpressure reaches 1280 torr, a final axial density gradient remains present of 188 . It should be mentioned that this gradient can be reduced by proper selection of the temperature gradient during the infiltration process (part 4 of this manuscript).

The composite part never achieves theoretical density but remains permeable for reactant and product gases to escape. Mass transport considerations and the etching effect of the HCl (that will develop as the MTS decomposes) hinders the complete densification of the porous structure.

\subsection{Infiltration as a function of bottom temperature}

It is the objective of the FCVI process to decrease densification time while maintaining uniform density throughout. By maintaining uniform deposition from the beginning, uniform final density can be assured. The thermal gradient is therefore an important 
aspect.

In order to study this effect, the thermal gradient across the preform during the infiltration is varied by changing the bottom temperature of the preform between $645-1010^{\circ} \mathrm{C}$ where as the top side remained at a constant temperature of $1200^{\circ} \mathrm{C}$ to ensure a high overall deposition rate.

Before attempts are made to increase the bottom temperature, the reproducibility of the infiltration is tested by production of 8 identical samples under the same conditions (bottom temperature of $760^{\circ} \mathrm{C}$ for all runs). The reactor has an inside diameter of 76 $\mathrm{mm}$.

\title{
4.1.1. Overall deposition
}

The average infiltration weight of the 8 identical runs is 123.4 $+/-4 \%$ gram. Weight increase is $2.84+/-78 \mathrm{~g} / \mathrm{hr}$. Infiltration duration is $43.5+/-6 \%$ hours. The bulk density obtained varies between 80 and $86 \%$ of the theoretical density.

No correlation is found between the fiber content (which varies $3.5 \%$ ) and the resulting matrix weight gain $(\mathrm{g})$ or rate $(\mathrm{g} / \mathrm{hr})$. This can be explained by the fact that a higher fiber content not necessarily means a greater surface area. This is also influenced by the fiber bundle packing density and consequently the pore size.

Hereafter, the bottom temperature is varied and resulting composite parts examined. The infiltration efficiency is plotted in figure 5 .

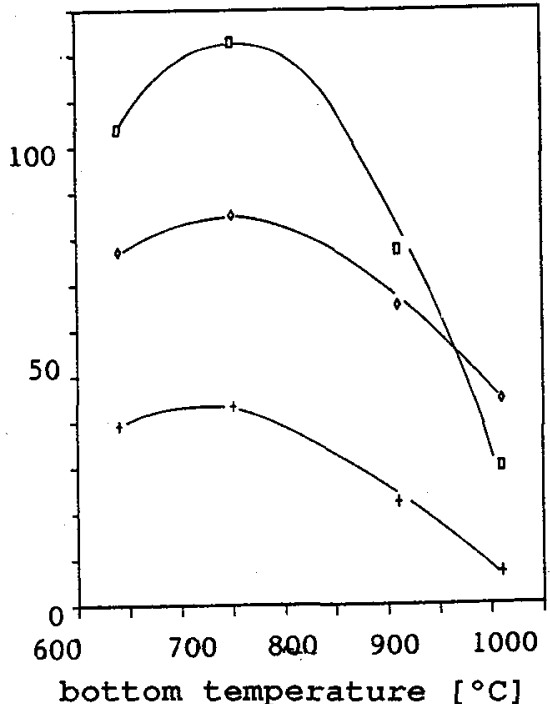

\author{
Figure 5 \\ Infiltration \\ efficiency as a \\ function of thermal \\ gradient across \\ the preform \\ D matrix weight [g] \\ $\checkmark$ fractional density \\ + infiltration \\ time [hrs]
}

Maximum weight gain is achieved at $760^{\circ} \mathrm{C}$ bottom temperature, but infiltration time is longest. A high gaspermeability can be maintained for a long time compared to the part with a higher or lower bottom temperature. If the MTS concentration in combination with a high temperature at any position in the part is too high, a too rapid deposition will block the gas paths and backpressure will rise. This occurs at the bottom cloth layer of the part when the temperature exceeds $760^{\circ} \mathrm{C}$ (temperature effect). Is the bottom temperature too low $\left(645^{\circ} \mathrm{C}\right)$ however, then the depletion of the 
gas is low. The blocking occurs more in the middle part of the preform and the cloth layers at the bottom of the part are not bonded to the rest. The ratio of the reactant depletion rate (concentration) and the reaction rate due to temperature is critical.

If the growth rate is more or less homogeneous throughout the part and independent on time, it is supposed that the backpressure rises by the homogeneous densification of the whole part and is not caused by decrease of the pore size at any specific location.

This means that any part of any thickness can be infiltrated when a proper thermal gradient (i.e. $27.5 \mathrm{k} / \mathrm{mm}$ ) is selected.

\subsubsection{Deposition gradients}

Figure 6 illustrates the intra bundle deposition as a function of bottom temperature as measured by means of image analysis performed on cross sections of the composite material. As bottom temperature is increased from 645 to $1010^{\circ} \mathrm{C}$ the matrix fraction initially rises from 35 to 45 volf, but decreases to 10 vols as temperatures greater than $760^{\circ} \mathrm{C}$ are selected.

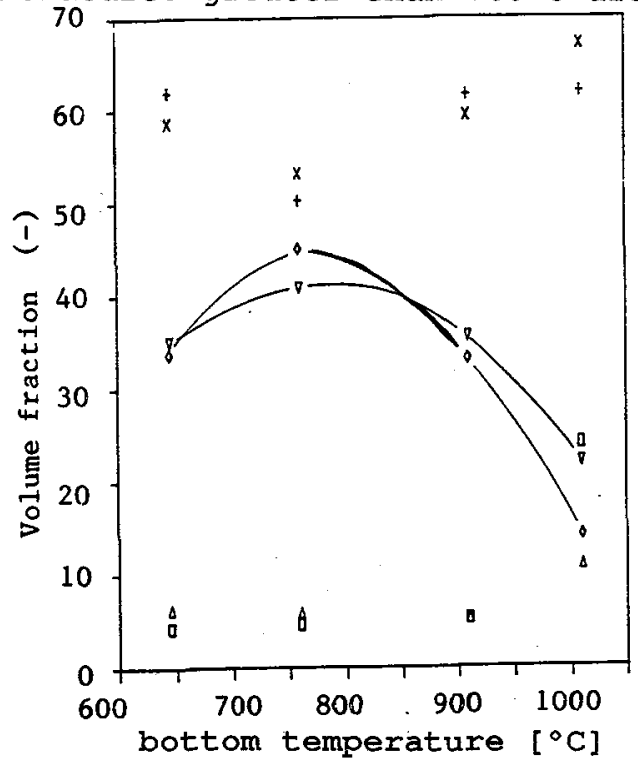

Figure 6. Matrix fraction in a nicalon fiber bundle as a function of bottom temperature

$\checkmark$ matrix top

$\nabla$ matrix bottom

+ fiber top

$x$ fiber bottom

0 pore top

$\Delta$ pore bottom

The highest intra bundle density is achieved at a thermal gradient of $27.5^{\circ} \mathrm{C} / \mathrm{mm}$.

Is the bottom temperature too high $\left(>850^{\circ} \mathrm{C}\right)$, so thermal gradient low, deposition will preferably occur on the bottom and depletion effects are clear at the top. Is the bottom temperature lower, then densification is more rapid at the top and after sealing of the fiber bundles further infiltration of the bundle is excluded.

\section{Conclusions}

The densification of a porous body is dependent on many process variables. Considering the nicalon fiber preform, an optimum thermal gradient of $27.5{ }^{\circ} \mathrm{C} / \mathrm{mm}$ is estimated. It is the objective 
to reduce infiltration time to be able to densify thick parts of great volume. Therefore, higher gas flow rates are suggested. The poor thermal stability of the nicalon fibers eliminate the operation at higher top temperatures.

The H2/MTS ratio can also be modified. An increase in MTS concentration should be balanced with a decrease in temperature to avoid premature sealing at any location in the part.

Operation to a higher backpressure value will enhance bulk density but increase infiltration times to a large extent.

Because of the long processing durations, models for the FCVI process can be very helpful in limiting costs. Validation of these models is of utmost importance. Without comparison of model output with real life situations, models are useless. Furthermore, modeling requires some input data. The physical properties of the solid (fibrous preform) and gaseous phases and not in the least kinetic data for the deposition reaction is a necessary provision.

An iterative comparison of model and experiments will bring us a better understanding of the FCVI process.

Goal of it all, is to achieve tough and strong fiber reinforced ceramic composites of complex shape and high and homogeneous density with a minimum of cost and effort.

\section{Acknowledgements}

The authors wish to thank J.C. Mclaughlin for the technical assistance, G. Klumperman and $s$. Jansen for performing the image analysis. R. Metselaar and A.M. Lankhorst for reviewing the manuscript.

This work was sponsored by the Innovative Research Program Tecnical Ceramics (IOP) of the Dutch Ministry of Economic Affairs and the U.S. Department of Energy, Fossil Energy Research and Technology Development Materials Program.

\section{References}

1. R. Naslain, F. Langlais, R. Fedou, "The CVI-processing of ceramic matrix composites", J. de Physique, coll C5 suppl. 5, 50, (1989), p c5-191. 